\title{
Secondary screening of strains of antagonists to a Phoma pathogen on sunflower
}

\author{
Lyubov Maslienko ${ }^{1 *}$, Aliya Voronkova ${ }^{1}$, Lyubov Datsenko ${ }^{1,2}$, Evgeniya Efimtseva ${ }^{1,2}$, and \\ Daria Punogina ${ }^{2}$ \\ ${ }^{1}$ V.S. Pustovoit All-Russian Research Institute of Oil Crops, 17, Filatova str., Krasnodar, 350038, \\ Russia \\ ${ }^{2}$ Kuban State University, 149, Stavropolskaya str., Krasnodar, 350040, Russia
}

\begin{abstract}
There are presented data of the first stage of the secondary screening of antagonist strains from a collection of the biological methods laboratory of V.S. Pustovoit All-Russian Research Institute of Oil Crops to the aggressive isolate of Phoma macdonaldii Boerema infecting sunflower. We used methods of 'agar blocks' and 'perforated Petri dishes'. As a result of a screening of 55 antagonist strains to Phoma macdonaldii pathogen we selected 17 promising strains-producers of microbiological preparations having biological efficiency exceeding $40.0 \%$. In control variant without seed treatment sunflower seedlings infection was up to $76.2 \%$, and maximal biological efficiency of laboratory samples from fungi-producers were determined for a strain M-24 Penicillium sp. (73.8 \%); from bacteria of a genus Bacillus - for a strain D-10 Bacillus sp. (74.2\%); from bacteria of a genus Pseudomonas - for a strain Sgc-1 Pseudomonas sp. (73.8 \%). Maximal colonizing activity were noted for fungi-producers M-24 Penicillium sp. (85.7\%) and Xk-1 Ch. olivaceum (71.4\%), as well as for bacteria of a genus Bacillus - 5B-1 B. subtilis $(71.4 \%)$ and a genus Pseudomonas - Oif 2-1 Pseudomonas sp. and 14-3 P. chlororaphis (71.4 \%) against Phoma infection in control of $70.0 \%$.
\end{abstract}

\section{Intriduction}

Last years the world agricultural production aimed to wider usage of elements of organic farming. Thus, development of biotechnologies of creation and application of the modern competitive microbiological preparations for agriculture became a high-priority task [1-6]. The biological methods laboratory of the V.S. Pustovoit All-Russian Research Institute of Oil Crops is one of the few ones in Russia which develops microbiological protection preparations for oil crops. As a base of a worked out by us conception of task-oriented development of microbiological preparations for protection of sunflower and other agricultural crops against diseases we use a search of antagonist strains which are safety for people, non-phytotoxic, possessing high activity in widely varying environments against a complex of pathogens, being of polyfunctional action. As a result of long-term researches we have created a collection of promising strains of fungi and bacteria-antagonists to a

Corresponding author: biometod@yandex.ru 
wide range of pathogens infecting oil and other agricultural crops. We studied protection actions of microbiological preparations for sunflower, soybean and rapeseed against pathogens of white rot, phomopsis, fusariose and downy mildew. We are continuing researches on microbiological protection of oil flax against fusariose pathogen $[7,8]$.

The subject of the present research was selected as harmfulness of Phoma rot (Phoma macdonaldii Boerema) on sunflower in the world [9-14] and last years in Russia [15, 16] has become more and more serious.

There are no released and registered microbiological preparations against the Phoma rot on sunflower in Russia.

Two bacterial bio-preparations were registered against the Phome rot on root crops: on sugar beet - BFTIM KS-2, L based on the bacterium Bacillus amyloliquefaciens and on carrots - Fitosporin-M, L based on Bacillus subtilis. We did not find in the literature information on the development of biological protection measures against the Phoma rot on sunflower, except for testing biological preparations against the Phoma rot on tea [17].

We isolated an aggressive isolate of the pathogen and conducted a primary screening of 65 antagonist strains from the laboratory collection. At the first stage of screening, we tested fungal strains represented by genera Trichoderma, Penicillium, Chaetomium, Trichothecium, Sordaria, Talaromyces, Aspergillus, Metarhizium and a class Basidiomycetes, and bacteria from genera Bacillus and Pseudomonas.

As a result of the primary screening to Phoma macdonaldii on sunflower, we selected 55 strains having one or more types of mechanism of action from the collection of antagonists.

In connection with the search among fungi and bacteria for promising strains-producers of microbiological preparations to protect sunflower from Phoma macdonaldii, an important aspect is not only their manifestation of antifungal activity in vitro, but also a protective and colonizing effect for seeds and seedlings in laboratory and fields. Therefore, the next step in our work was to identify, among the selected antagonists, the most active strains-producers of microbiological preparations having a protective and colonizing effect against Phoma macdonaldii in conditions of artificial infection in the laboratory in a moist chamber (the first stage of the secondary screening).

\section{Materials and methods}

To conduct the first stage of the secondary screening based on the promising strains, we accumulated laboratory samples of microbiological preparations in a preparative form 'liquid culture' (LC). Antagonists were cultivated on liquid nutrient mediums: fungi - on Rudakov's, bacteria of a genus Bacillus - Tylon's-3, of a genus Pseudomonas - King's B. Deep cultivation were done in nutator with a spin speed $200 \mathrm{rpm}$, in Erlenmeyer flasks, of a volume $750 \mathrm{ml}$, at medium volume $150 \mathrm{ml}$. Amount of colony-forming units (CFU) in a liquid culture (LC) of microbiological preparations was determined by a Koch's method.

To determine the protective effect of laboratory samples of microbiological preparations in a moist chamber, we used the method of "agar blocks" developed by Zaichuk (1983). For this, sunflower seeds of the variety R-453 we treated manually with the laboratory samples of the microbiological preparations in Erlenmeyer flasks, in circular rotational movements, with a preparation application rate of 3.0 liter per a ton and a working fluid rate of 10 liter per a ton. After a day, the treated seeds were laid out in a germinator on moistened filter paper with a layer of cotton, an agar block with pathogen mycelium, $3.0 \times 4.0 \mathrm{~mm}$ in size, was applied on top and a moist chamber was created. Empirically, we have established the optimal nutrient medium is potato-sucrose agar (KSA) and the pathogen cultivation period is 10 days. As a control we used untreated seeds infected with a pathogen. Accounting for 
the infection level on sunflower seedlings was carried out in seven days after infecting with a pathogen.

The colonizing activity of the strains that showed the best protective effect by the method of "agar blocks" we determined by the method of "perforated Petri dishes" using the modified Antonova and Saukova's method (2005). For this, two-day sunflower seedlings obtained by germinating seeds treated with the laboratory samples of the microbiological preparations were placed in the holes of a perforated Petri dish so that the tips of the roots touched the colony of pathogenic isolate of Phoma macdonaldii, the exposure time was 3 hours at a temperature of $+25.0^{\circ} \mathrm{C}$. In the control variant, the tips of the sunflower roots were immersed into filter paper moistened with sterile water. Then the infected and control seedlings were kept in a moist chamber for four days.

The infection degree of sunflower seedlings by the pathogen of Phoma macdonaldii was assessed according to the scale we developed:

0 points - healthy seedlings

1 point - darkening of the root tip, intensive formation of lateral roots;

2 points - darkening of the root by a third or to the middle, but the intensive formation of lateral roots;

3 points - overwinding of rot in the middle of the root or between the hypocotyl and the root, but the intensive formation of lateral roots;

4 points - root rotting to the middle or overwinding of rot between the hypocotyl and the root, lateral roots are poorly developed;

5 points - complete root rotting, lateral roots are poorly developed or absent;

1-3 - viable seedlings;

4-5 - non-viable seedlings.

Accounting pf the biological effectiveness of the laboratory samples when determining the colonizing activity was conducted according to the spread of the disease, taking into account the infection degree of sunflower seedlings by the Phoma macdonaldii pathogen in a day after infection.

An experiment included three repetitions. The biological effectiveness of the laboratory samples of the microbiological preparations was determined by the formula:

$$
\mathrm{C}=100(\mathrm{a}-\mathrm{b}) / \mathrm{a},
$$

where: $\mathrm{C}$ - biological activity, \%;

a - amount of diseased plants in a control;

$\mathrm{b}$ - amount of diseased plants in a variant.

\section{Results and discussing}

As a result of the evaluation of the laboratory samples of the microbiological preparations in the preparative form of LC based on 55 strains of fungi and bacteria-antagonists isolated in the initial screening, we selected 17 promising strains-producer that showed biological efficacy excessing $40.0 \%$ in conditions of high artificial infection of sunflower with Phoma macdonaldii in the laboratory using the "agar block" method. Ten strains-producers of the microbiological preparations demonstrated the maximum efficiency against the pathogen in seven days after infection (Table. 1).

Among 23 fungal antagonist strains, we found out the high biological efficiency of the laboratory samples for seven strains, while the maximum was found in M-24 Penicillium sp. (73.8 \%) and Xk-1 Chaetomium olivaceum (67.2\%) under artificial infection of sunflower seedlings with Phoma macdonaldii in the control without treatment an average of $76.2 \%$. 
Table 1. Efficiency of seed treatment of sunflower variety R-453 with the laboratory samples of the microbiological preparations containing fungi or bacteria-producers against Phoma macdonaldii in lab conditions under artificial infection using a method of 'agar blocks'

\begin{tabular}{|c|c|c|}
\hline Variant & Titer, CFU per g & Biological efficiency, $\%$ \\
\hline Control, without treatment & - & $76.2^{*}$ \\
\hline \multicolumn{3}{|c|}{ Fungi-producers } \\
\hline M-24 Penicillium sp. & $7.8 \times 10^{9}$ & 73.8 \\
\hline Xk-1 Chaetomium olivaceum & $4.0 \times 10^{7}$ & 67.2 \\
\hline T-2 Trichoderma sp. & $2.8 \times 10^{9}$ & 60.6 \\
\hline Pbc-1 P. brevicompactum & $9.0 \times 10^{9}$ & 60.6 \\
\hline Tt-1 Talaromyces trachispermus & $6.8 \times 10^{7}$ & 60.6 \\
\hline Pr-1 Penicillium rugulosum & $6.0 \times 10^{9}$ & 47.5 \\
\hline A-1 Basidiomycetes & $5.4 \times 10^{7}$ & 47.5 \\
\hline \multicolumn{3}{|c|}{ Bacteria-producers } \\
\hline D-10 Bacillus sp. & $3.8 \times 10^{10}$ & 74.2 \\
\hline 5-3 Bacillus sp. & $3.0 \times 10^{10}$ & 60.6 \\
\hline B-5 B. licheniformis & $4.8 \times 10^{10}$ & 60.6 \\
\hline 1a B. polymyxa & $5.4 \times 10^{10}$ & 54.0 \\
\hline 11-1 Bacillus sp. & $2.0 \times 10^{10}$ & 47.5 \\
\hline 5B-1 B. subtilis & $5.0 \times 10^{10}$ & 41.2 \\
\hline K 1-2 Bacillus sp. & $4.4 \times 10^{10}$ & 41.2 \\
\hline Sgc-1 Pseudomonas sp. & $2.8 \times 10^{11}$ & 73.8 \\
\hline 14-3 P. chlororaphis & $3.0 \times 10^{11}$ & 47.5 \\
\hline Oif 2-1 Pseudomonas sp. & $1.8 \times 10^{11}$ & 40.9 \\
\hline
\end{tabular}

Among 24 bacterial strains-producers of the genus Bacillus, the high efficiency of laboratory samples against the Phoma macdonaldii pathogen was also found for seven strains, with the maximum in D-10 Bacillus sp. (74.2\%), 5-3 Bacillus sp. and B-5 B. licheniformis $(60.6 \%)$.

Three strains from eight bacterial antagonist strains of the genus Pseudomonas had the high efficiency of the laboratory samples against Phoma macdonaldii, while the maximum was established in Sgc-1 Pseudomonas sp. (73.8 \%).

We determined colonizing activity of strains-producers that showed the best protective effect by the method of "agar blocks" in a day after infection. It should be emphasized we infected only the tips of the roots of the two-day-old sunflower seedlings which touched the pathogen colony for three hours. Thus, infecting the roots that have grown from the treated seeds, we can view the colonizing activity of the strains-producers that is their ability to move beyond the growing root.

It is important to say, that already in a day after infection with Phoma macdonaldii we saw more intense root damage in $70.0 \%$ of the seedlings of the control variant (2-3 points). Whereas in the best variants of strains-producers, the roots were 80.0-90.0\% healthy and only 10.0-20.0\% showed only darkening of the tip or third of the root (0-2 points) (Table 2$)$.

Among the fungal strains, the fungi-producers M-24 Penicillium sp. and Xk-1 Ch. olivaceum demonstrated maximal colonizing activity and protection effect. When seedlings of sunflower variety R-453 were infected with Phoma macdonaldii up to $70.0 \%$, biological effectiveness of the best fungal strains-producers was 71.4-85.7 \%. Among bacterial strains from a genus Bacillus, the strain 5B-1 B. subtilis had the highest biological effectiveness 
(71.4 \%). The strains Oif 2-1 Pseudomonas sp. and 14-3 P. chlororaphis appeared to be the most effective (71.4\%) among all of a genus Pseudomonas.

Table 2. Influence of treatment of sunflower seeds of variety R-453 with the laboratory samples of the microbiological preparations on a level of seedlings infection with Phoma macdonaldii in lab conditions under artificial infection using a method of 'agar blocks'

\begin{tabular}{|c|c|c|c|c|c|c|c|}
\hline \multirow{3}{*}{ Variant } & \multirow{3}{*}{$\begin{array}{c}\text { Titer, } \\
\text { CRU per } \\
\text { g }\end{array}$} & \multicolumn{5}{|c|}{ Infected seedlings, $\%$} & \multirow{3}{*}{$\begin{array}{l}\text { Biological } \\
\text { efficiency, \%, }\end{array}$} \\
\hline & & \multicolumn{4}{|c|}{$\begin{array}{l}\text { Infection level of the } \\
\text { main root, points }\end{array}$} & \multirow[t]{2}{*}{ Totally } & \\
\hline & & 0 & 1 & 2 & 3 & & \\
\hline $\begin{array}{l}\text { Control, without } \\
\text { treatment }\end{array}$ & - & 0 & 0 & 30.0 & 40.0 & $70.0^{*}$ & - \\
\hline \multicolumn{8}{|c|}{ Fungi-producers } \\
\hline M-24 Penicillium sp. & $7.8 \times 10^{9}$ & 90.0 & 0 & 10.0 & 0 & 10.0 & 85.7 \\
\hline $\begin{array}{l}\text { Xk-1 Chaetomium } \\
\text { olivaceum }\end{array}$ & $4.0 \times 10^{7}$ & 80.0 & 0 & 20.0 & 0 & 20.0 & 71.4 \\
\hline $\begin{array}{l}\text { Pr-1 Penicillium } \\
\text { rugulosum }\end{array}$ & $6.0 \times 10^{9}$ & 70.0 & 0 & 0 & 30.0 & 30.0 & 57.1 \\
\hline T-2 Trichoderma sp. & $2.8 \times 10^{9}$ & 60.0 & 30.0 & 0 & 10.0 & 40.0 & 42.9 \\
\hline $\begin{array}{l}\text { Tt- } 1 \text { Talaromyces } \\
\text { trachispermus }\end{array}$ & $6.8 \times 10^{7}$ & 60.0 & 10.0 & 10.0 & 20.0 & 40.0 & 42.9 \\
\hline \multicolumn{8}{|c|}{ Bacteria-producers } \\
\hline 5B-1 B. subtilis & $5,0 \times 10^{10}$ & 80.0 & 0 & 20.0 & 0 & 20.0 & 71.4 \\
\hline 5-3 Bacillus sp. & $3,0 \times 10^{10}$ & 70.0 & 0 & 0 & 30.0 & 30.0 & 57.1 \\
\hline B-5 B. licheniformis & $4,8 \times 10^{10}$ & 70.0 & 10.0 & 10.0 & 10.0 & 30.0 & 57.1 \\
\hline 11-1 Bacillus sp. & $2,0 \times 10^{10}$ & 70.0 & 20.0 & 10,0 & 0 & 30.0 & 57.1 \\
\hline $\begin{array}{l}\text { Oif 2-1 Pseudomonas } \\
\text { sp. }\end{array}$ & $1,8 \times 10^{11}$ & 80.0 & 0 & 10.0 & 10.0 & 20.0 & 71.4 \\
\hline 14-3 P. chlororaphis & $3,0 \times 10^{11}$ & 80.0 & 0 & 10.0 & 10.0 & 20.0 & 71.4 \\
\hline Sgc-1 Pseudomonas sp. & $2,8 \times 10^{11}$ & 70.0 & 20.0 & 10.0 & 0 & 30.0 & 57.1 \\
\hline \multicolumn{8}{|c|}{$\begin{array}{l}\text { Note: a degree of sunflower seedlings infection, points: } \\
0 \text { - healthy root; } \\
1 \text { - darkening of root tips, formation of lateral roots; } \\
2 \text { - darkening of root by one third or to the middle, formation of lateral roots; } \\
3 \text { - overwinding of rot in the middle part of a root or between hypocotyl and root, } \\
\text { formation of lateral roots }\end{array}$} \\
\hline
\end{tabular}

All the selected promising antagonist strains will be evaluated in the following screening stages. We will determine the growth-stimulating activity for a sunflower crop and the protective effect of laboratory samples of the microbiological preparations under artificial infection with a pathogen in the soil in laboratory and field. We plan to develop the microbiological preparations in the form of "wettable powder" with a prolonged shelf life on a base of the strains-producers that showed the maximum protective and colonizing effects, and having a growth-stimulating activity.

\section{Conclusion}

As a result of the first stage of the secondary screening of 55 antagonist strains to Phoma macdonaldii on sunflower we selected 17 promising strains-producers of 
microbiological preparations having shown biological activity to infected seedlings more than $40.0 \%$.

Maximal efficiency of the laboratory samples were stated for the strains: from fungiproducers - M-24 Penicillium sp. (73.8\%); from bacteria of a genus Bacillus - D-10 Bacillus sp. (74.2 \%); from bacteria of a genus Pseudomonas - Sgc-1 Pseudomonas sp. (73.8 \%) comparing to a control variant without seed treatment with sunflower seedlings infection of $76.2 \%$.

Fungi-producers M-24 Penicillium sp. (85.7 \%) and Xk-1 Ch. olivaceum (71.4\%), as well as bacteria from a genus Bacillus - 5B-1 B. subtilis $(71.4 \%)$ and a genus Pseudomonas - Oif 2-1 Pseudomonas sp. and 14-3 P. chlororaphis (71.4 \%) demonstrated maximal colonizing activity and protection effect compared to a control variant without seed treatment with sunflower seedlings infection of $70.0 \%$.

This work was financially supported by a grant from the Russian Fund of Fundamental Researches (RFFR) and the Administration of the Krasnodar region r_Nastavnik No 19416-235003.

\section{References}

1. I. Mnif, D. Ghribi, Crop Protection, 77, 52-64, (2015) https://doi.org/10.1016/j.cropro.2015.07.017

2. Ch. Keswani, H. Dilnashin, H. Birla, Surya PratapSingh, Rhizosphere, 11, 100155 (2019) https://doi.org/10.1016/j.rhisph.2019.100155

3. P. Fickers, American Journal of Biochemistry and Biotechnology, 8(1), 38-43(2012)

4. R.K. Alaa, B. Alden Sanaa, World Journal of Experimental Biosciences, 2(2), 59-63 (2014)

5. T. Wang, Y. Liang, M. Wu, Z. Chen, J. Lin, L. Yang, Chinese J. Chem. Eng., 23(4), 744-754 (2015)

6. E. P. Grijalba, C. Espinel, P. E. Cuartas, M. L. Chaparro, L. F. Villamizar, Fungal Biology, 122(11), 1069-1076 (2018) https://doi.org/10.1016/j.funbio.2018.08.010

7. L.V. Maslienko, E.Yu. Shipievskaya, N.S. Zakharchenko, Ya.I. Buryanov, and V.S. Shevelukha, Biotechnology in Russia, 3, 50-56 (2010) https://agris.fao.org/agrissearch/search.do?recordID=RU2010000410

8. L.V. Maslienko, A.Kh. Voronkova, L.A. Datsenko, E.A. Efimtseva, Oil Crops, 4(180), 128-132 (2019) https://elibrary.ru/download/elibrary_41423725_12029397.pdf

9. S.L. Saukova, M.V. Ivebor, T.S. Antonova, N.M. Araslanova, Oil Crops, 2(159160), 167-172 (2014) https://elibrary.ru/download/elibrary_22996216_39448525.pdf

10. N.M. Araslanova, S.L. Saukova, T.S. Antonova, Oil Crops, 4(176), 162-168 (2018) https://elibrary.ru/download/elibrary_36853224 98685433.pdf

11. B. Dedić. Pestic. Phytomed. (Belgrade), 27(4), 299-303 (2012).

12. J. Lević, S. Stanković, V. Krnjaja, A. Bočarov - Stančić, D. Ivanović , Pesticides and Phytomedicine, 27(1), 33-40, (2012)

13. C. Seassau, G. Dechamp-Guillaume, E. Mestries, P. Debaeke, European Journal of Agronomy, 43, 185-193 (2012) https://doi.org/10.1016/j.eja.2012.07.002

14. S. N. Maširević, S. S. Medić-Pap, and N. Terzić, B. P. Dedić, I. Dž. Balalić, Jour. Nat. Sci, Matica Srpska Novi Sad, 126, 57-65, (2014)

15. X. Zhao, Z. Chen, L. Yu, D. Hu, B. Song, Pesticide Biochemistry and Physiology, 147, 46-50 (2018) https://doi.org/10.1016/j.pestbp.2017.08.014

16. N. Yan, R. Na, R. Jia, J. Zhang and J. Zhao, OCL, 27, 12, 5 (2020) https://doi.org/10.1051/ocl/2020014

17. F.J. Quiroz, J.P. Edwards Molina, G.A.A. Dosio, Field Crops Research, 160, 31-40, (2014) https://doi.org/10.1016/j.fcr.2014.02.011 